\title{
Prevalence and Determinants of Depression among Type 2 Diabetic Patients in Tabuk City, Saudi Arabia
}

\author{
Faisal Najem Al-Atawi ${ }^{1}$, Mashael Abdullah Al-Atawi ${ }^{1}$, Ashwag Ahmed Al-Shehri², \\ Saif Mohammed Al-amri', Nawal Khalaf Al-anazi ${ }^{1}$, Majed S. Al-Qahtani ${ }^{3}$

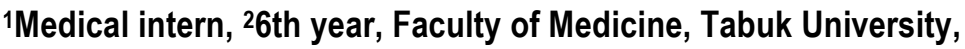 \\ ${ }^{3}$ King Fahd Specialist hospital, Tabuk, Saudi Arabia
}

\begin{abstract}
Background: Compared with patients with diabetes alone, patients with depression and diabetes have been shown to have poorer self-management and poor adherence to antidiabetics, lipid-lowering and antihypertensive treatment.

Objectives: To investigate the prevalence and determinants of depression in patients with T2DM attending general hospitals, Tabuk, Saudi Arabia.

Subjects and Methods: A cross-sectional community based study was conducted in Tabuk city, Saudi Arabia. A representative random sample of diabetic type 2 Saudi patients aged 18 years or above who attended out patients clinics of the two main general hospitals, belonging to Ministry of health (King Khalid and King Fahd specialist hospitals) throughout the study period (20 July to 20 Aug, 2016) constituted the population for the study. Data collection questionnaire developed by the researchers composed of two parts; Personal characteristics and diabetes-related variables. The Arabic version of the Patient Health Questionnaire (PHQ-9) was utilized for diagnosis of depression.

Results: The study included 221 patients with a response rate of $61 \%$. Approaching one-third of them (34.8\%) aged between 50 and 59 years and $4.1 \%$ aged over 70 years. Males represent $51.6 \%$ of them. Obesity and extreme obesity were reported among $35.7 \%$ and $5.5 \%$ of the patients, respectively. Family history of depression was reported among 37 patients representing $16.7 \%$ of the respondents. Depression was reported among almost most of type 2 diabetic patients
\end{abstract}

\section{INTRODUCTION}

The lifetime prevalence of major depression in adults is estimated to be 7 to 12 percent in men and 20 to 25 percent in women. The prevalence of depression in patients in primary care settings ranges from 5 to 10 percent.The rates are significantly higher in persons with certain medical conditions, including obesity, diabetes mellitus, cancer, and a history of myocardial infarction. ${ }^{1}$ The World Health Organization reported that 300 million people will suffer from diabetes by 2025. ${ }^{2}$ In the Kingdom of Saudi Arabia; the number of people with diabetes is increasing due to population growth, aging, urbanization, and increasing prevalence of obesity and physical inactivity. The overall prevalence of diabetes was $23.7 \%$, with $26.2 \%$ being males and $21.5 \%$ females. The
(77.8\%). It was mild among $32.1 \%$ of them, moderate among $25.8 \%$ whereas it was moderately severe or severe among $19.9 \%$ of them.Low income patients ( $\leq 5000 \mathrm{SR} /$ month), those with family history of depression, treated with insulin and having diabetic complication were more likely to be depressed than their counterparts.

Conclusion: Depression was prevalent among type 2 diabetic patients attended general hospitals in Tabuk city. Implementing screening program for diabetic patients regarding depression through trained family physicians especially for high risk groups as well as referral ofthose suffering from severe depression to psychiatrists as early as possible are recommended.

Key Words: Diabetes type 2, Depression, Patient Health Questionnaire, Insulin, Complications.

\section{*Correspondence to:}

Dr. Majed S. Al-Qahtani

Associate consultant of Family Medicine

Medical Director, King Fahd Specialist hospital, Tabuk.

Article History:

Received: 13-10-2016, Revised: 18-10-2016, Accepted: 27-10-2016

\begin{tabular}{|l|c|}
\hline \multicolumn{2}{|c|}{ Access this article online } \\
\hline $\begin{array}{l}\text { Website: } \\
\text { www.ijmrp.com }\end{array}$ & Quick Response code \\
\hline DOI: & \\
10.21276/ijmrp.2016.2.6.009 & \\
\hline
\end{tabular}

calculated age-adjusted prevalence for Saudi population for the year 2000 was $21.9 \%$. Diabetes mellitus is more prevalent among Saudis living in urban areas $25.5 \%$ compared to rural areas as $19.5 \%{ }^{3}$

Diabetes is a major contributor to the global burdenof disease and a growing number of studies showlinks between depression and diabetes. ${ }^{4-7}$ The rate of depression in people with diabetes is much higher than in the general population. ${ }^{8} \mathrm{~A}$ meta-analysis including 20 controlled studies found that the riskof depression in the diabetic groups was two-foldhigher than that in the non-diabetic comparisongroups. ${ }^{9}$ This relative risk of depression is greaterthan found in most other chronic diseases. ${ }^{10}$ The risk of depression 
increases in women with diabetes. ${ }^{8}$ The prevalence of depression is higher in patientswith diabetes who have long-term complications. ${ }^{11,12}$

Compared with patients with diabetes alone, patients with depression and diabetes have been shown to have poorer selfmanagement and poor adherence to antidiabetic, lipid-lowering and antihypertensive treatment. ${ }^{13}$ They are more likely to have higher cardiovascular risk factors like smoking, obesity, sedentary lifestyle, and uncontrolled hyperglycaemia. ${ }^{12}$ Depression may be an important barrier to effective diabetes management. Patients with depression and diabetes are more likely to have higher macrovascular and microvascular complications ${ }^{9}$ and higher mortality rates. ${ }^{14}$

Despite numerous investigations, the underlying pathophysiologies of the metabolic abnormalities are poorly understood. A possible role play the increases counter-regulatory hormone release involved in glucose homeostasis, alterations in the glucose transport function and increased inflammatory activation triggered by depression. ${ }^{10}$ Psychiatric disorders could affect patients' quality of life. Such effects may be due to alterations in diet, constant dependence on medication, short and long-term side effects and the burden of costs. ${ }^{15}$

Previous studies have shown individuals who are insulin-resistant may have higher serotonin concentrations and may be more prone to depression and even suicide. ${ }^{9}$

While depression may contribute to poor diabetes-related outcomes, diabetes and its complications may also contribute to poor depression outcomes. . $^{10,13,16}$

In the absence of systematic screening, family physicians miss at least $50 \%$ of cases of major depression. The 9-item Patient Health Questionnaire (PHQ-9) is a potentially valuable tool for diagnosis and management of depression. ${ }^{17}$ The PHQ-9 has been recommended for depression screening in primary care. ${ }^{18}$

This study aimed to investigate the prevalence and determinants of depression in patients with T2DM attending general hospitals, Tabuk, Saudi Arabia.

\section{SUBJECTS AND METHODS}

A cross-sectional community based study was conducted in Tabuk city, Saudi Arabia. In Tabukcity, there are two main general hospitals, belonging to Ministry of health (King Khalid and King Fahd specialist hospitals) where the study was conducted. All diabetic type 2 Saudi patients aged 18 years or above who attended out patients clinics of the involved hospitals throughout the study period (20 July to 20 Aug, 2016) constituted the target population for the study.

Assuming that the prevalence of major depressive disorder among type 2 diabetic patients was $6.2 \%{ }^{19}$

According to the formula of sample size calculation: $\mathrm{N}=\underline{\mathrm{T}^{2} \times \mathrm{P}(1-\mathrm{P})}$

$$
M^{2}
$$

Where $\mathrm{N}=$ required sample size. $\mathrm{T}=$ confidence level at $95 \%$ (standard value of 1.96), $\mathrm{P}=$ estimated prevalence of disease in the project area and $M=$ margin of error at $5 \%$ (standard value of 0.05). The sample size was a minimum of 362 patients. The sample size was almost equally distributed over the two hospitals (King Khalid hospital and King Fahd specialist hospital). An average of two week was spent in each hospital to randomly select patients.
Data collection questionnaire developed by the researchers composed of two parts; Personal characteristics: Age, sex, education, employment, marital status, number of children, presence of co-morbidity (e.g., hypertension, heart disease, bronchial asthma, renal disease, etc.), smoking and family history of depression and diabetes-related variables: duration of disease, insulin treatment, compliance with therapy, presence of complications. In addition to data collected from patient's file (number of follow-up visits over the last year, last fasting blood glucose level, last HBA1c, weight and height). Fasting blood sugar level $(\mathrm{mg} / \mathrm{dl})$ will be assessed for diabetic patients. The level of control of diabetes as indicated by fasting blood sugar control was determined according to Campbell and Braithwaite, ${ }^{20}$ as follows: Good (<126 mg/dl), borderline (126-180 mg/dl) and poor (>180 $\mathrm{mg} / \mathrm{dl})$.

Glycosylated hemoglobin (HBA1c) Levels above 9\% was considered as poor control, and levels above $12 \%$ will be considered as very poor control. ${ }^{21}$ Body mass index (BMI) was calculated by dividing the weight in $\mathrm{kg}$ by the square of the length in meter. Participants were categorized, based on their BMI values into four subgroups; normal (BMl from 18.5 to $24.9 \mathrm{~kg} / \mathrm{m}^{2}$ ), overweight (BMl from 25 to $29.9 \mathrm{~kg} / \mathrm{m}^{2}$ ), Obese (BMl from 30 to $\left.39.9 \mathrm{~kg} / \mathrm{m}^{2}\right)$, and extremely obese (BMl $\left.\geq 40 \mathrm{~kg} / \mathrm{m}^{2}\right)$.

The Arabic version of the Patient Health Questionnaire (PHQ-9): This questionnaire is composed of 9 statements. The PHQ- 9 is a multipurpose instrument for screening, diagnosing, monitoring and measuring the severity of depression. The PHQ-9 incorporates DSM-IV depression diagnostic criteria with other leading major depressive symptoms into a brief self-report tool. The tool rates the frequency of the symptoms which factors into the scoring severity index. The PHQ-9 is brief and useful in clinical practice. The PHQ-9 is completed by the patient in minutes and is rapidly scored by the clinician. The PHQ-9 can also be administered repeatedly, which can reflect improvement or worsening of depression in response to treatment. ${ }^{22}$ Liuet al. ${ }^{23}$ reported that the PHQ-9 had a good internal consistency $(\alpha=.80)$ and test-retest reliability (intra-class correlation coefficient $=0.87$ ). The $P H Q-9$ is significantly correlated with the external validators such as the 17item of Hamilton Rating Scale and the Short Form of the Quality of Life Enjoyment and Satisfaction Questionnaire $(P<0.001)$. A PHQ9 score of 10 or higher had a sensitivity of 0.86 and a specificity of 0.94 for recognizing major depressive disorders. The PHQ-9 has 9 questions with a score ranging from 0 to 3 for each setting to consider initiating treatment with antidepressants. ${ }^{24}$ Table 1 describes the provisional diagnoses for scoring classes.

Table 1: PHR-p classification

\begin{tabular}{ccl}
\hline PHQ-9 score & Provisional diagnosis \\
\hline - & $0-4$ & None \\
- & $5-9$ & Mild depression \\
- & $10-14$ & Moderate depression \\
- & $15-19$ & Moderately severe depression \\
- & $20-27$ & Severe depression \\
\hline
\end{tabular}

Prior to data collection, the investigators informedall potential participants regarding the objectives of the study. They were assured that no harm is ever expected to occur if they decide to 
participate in the study. All diabetic subjects who obtained scores $>10$ were referred to a psychiatrist to establish the final diagnosis and to start management accordingly.

Statistical Package for Social Sciences (SPSS) software version 21.0 was used for computerized data entry and analysis. Descriptive statistics (number, percentage for categorical variables and mean, standard deviation and range for continuous variables) and analytic statistics using Chi Square tests $\left(X^{2}\right)$ to test for the association and/or the difference between two categorical variables were applied. P-value equal or less than 0.05 was considered statistically significant.

\section{RESULTS}

The study included 221 patients with a response rate of $61 \%$. Table 2 summarizes their socio-demographic characteristics. Approaching one-third of them (34.8\%) aged between 50 and 59 years and $4.1 \%$ aged over 70 years. Males represent $51.6 \%$ of them. Majority of the participants $(77.4 \%)$ were married. Most of them $(72.8 \%)$ had at least four children. About half of them $(45.3 \%)$ were house wives whereas $22.6 \%$ were governmental employees. The income of $60.6 \%$ of them was below SR/month. Current smoking was reported among $24.4 \%$ of the participants whereas $9.5 \%$ were ex-smokers.

Table 2: Socio-demographic characteristics of the participants

\begin{tabular}{|c|c|c|}
\hline & Frequency $(\mathrm{N}=221)$ & Percentage \\
\hline \multicolumn{3}{|l|}{ Age in years } \\
\hline $30-39$ & 45 & 20.4 \\
\hline $40-49$ & 56 & 25.3 \\
\hline $50-59$ & 77 & 34.8 \\
\hline $60-69$ & 34 & 15.4 \\
\hline$\geq 70$ & 9 & 4.1 \\
\hline \multicolumn{3}{|l|}{ Gender } \\
\hline Male & 114 & 51.6 \\
\hline Female & 107 & 48.4 \\
\hline \multicolumn{3}{|l|}{ Marital status } \\
\hline Single & 11 & 5.0 \\
\hline Married & 171 & 77.4 \\
\hline Divorced & 15 & 6.8 \\
\hline Widowed & 24 & 10.8 \\
\hline \multicolumn{3}{|l|}{ Number of children } \\
\hline None & 13 & 5.9 \\
\hline 1 & 11 & 5.0 \\
\hline 2 & 15 & 6.8 \\
\hline 3 & 21 & 9.5 \\
\hline$\geq 4$ & 161 & 72.8 \\
\hline \multicolumn{3}{|l|}{ Job } \\
\hline Governmental employee & 50 & 22.6 \\
\hline Private sector employee & 19 & 8.6 \\
\hline Business & 18 & 8.1 \\
\hline House wife & 100 & 45.3 \\
\hline Retired & 34 & 15.4 \\
\hline \multicolumn{3}{|c|}{ Income in Saudi Riyals/month } \\
\hline$\leq 5000$ & 134 & 60.6 \\
\hline $5001-10000$ & 47 & 21.3 \\
\hline$>10000$ & 40 & 18.1 \\
\hline \multicolumn{3}{|l|}{ Smoking history } \\
\hline Current smoker & 54 & 24.4 \\
\hline Non-smoker & 146 & 66.1 \\
\hline Ex-smoker & 21 & 9.5 \\
\hline
\end{tabular}


Faisal N Al-Atawi et al. Depression among Type 2 Diabetic Patients in Tabuk City

Table 3: Medical characteristics of the participants

\begin{tabular}{|c|c|c|}
\hline & Frequency $(\mathrm{N}=221)$ & Percentage \\
\hline \multicolumn{3}{|l|}{$\mathrm{BMI}\left(\mathrm{kg} / \mathrm{m}^{2}\right)$} \\
\hline Underweight & 4 & 1.8 \\
\hline Normal & 34 & 15.4 \\
\hline Overweight & 92 & 41.6 \\
\hline Obese & 79 & 35.7 \\
\hline Extremely obese & 12 & 5.5 \\
\hline \multicolumn{3}{|l|}{ Family history of depression } \\
\hline Yes & 37 & 16.7 \\
\hline No & 184 & 83.3 \\
\hline \multicolumn{3}{|c|}{ History of other chronic diseases } \\
\hline Yes & 94 & 42.5 \\
\hline No & 127 & 57.5 \\
\hline \multicolumn{3}{|l|}{ Number of daily drugs taken } \\
\hline One & 23 & 10.4 \\
\hline Two & 74 & 33.5 \\
\hline Three & 67 & 30.3 \\
\hline Four and more & 57 & 25.8 \\
\hline \multicolumn{3}{|l|}{ Insulin therapy } \\
\hline Yes & 112 & 50.7 \\
\hline No & 109 & 49.3 \\
\hline \multicolumn{3}{|c|}{ Compliance with diabetic therapy } \\
\hline Yes, perfect & 105 & 47.5 \\
\hline Yes, to some extent & 94 & 42.5 \\
\hline No & 22 & 10.0 \\
\hline \multicolumn{3}{|l|}{ Diabetic complications } \\
\hline Yes & 52 & 23.5 \\
\hline No & 169 & 76.5 \\
\hline \multicolumn{3}{|c|}{ Number of follow-up visits/year } \\
\hline One & 17 & 7.7 \\
\hline Two & 86 & 38.9 \\
\hline Three & 85 & 38.5 \\
\hline More than three & 33 & 14.9 \\
\hline \multicolumn{3}{|c|}{ Fasting blood glucose (mg/dl) } \\
\hline Good $(<126)$ & 66 & 29.9 \\
\hline Borderline (126-180) & 114 & 51.5 \\
\hline Poor $(>180)$ & 41 & 18.6 \\
\hline \multicolumn{3}{|l|}{$\mathrm{HbA1c} \%$} \\
\hline Controlled (<9\%) & 162 & 73.3 \\
\hline Poor controlled (9-12\%) & 58 & 26.2 \\
\hline Very poor controlled (>12\%) & 1 & 0.5 \\
\hline
\end{tabular}

Obesity and extreme obesity were reported among $35.7 \%$ and $5.5 \%$ of the patients, respectively. Family history of depression was reported among 37 patients representing $16.7 \%$ of the respondents. Less than half of the participants $(42.5 \%)$ had history of chronic disease other than DM. Almost one-fourth of those $(25.8 \%)$ reported taking at least 4 drugs on daily basis for their medical problems. About one-half of the type 2 diabetic patients $(50.7 \%)$ reported insulin therapy. Approximately half of the patients $(47.5 \%)$ claimed that they are perfectly compliant with diabetic therapy whereas only 22 patients representing $10 \%$ of the participants reported that they are not compliant with diabetic therapy. Diabetic complications were reported among $23.5 \%$ of type 2 diabetic patients. Follow-up visits exceeded 3 per year among $14.9 \%$ of patients. Fasting blood glucose level was poor among more 18.6 of the participants whereas it was borderline among $51.5 \%$ of them. According to glycated hemoglobin, 
diabetes was poorly controlled among $26.2 \%$ of patients and very poorly controlled among $0.5 \%$ of them. Table 3

As shown in figure 1, depression was reported among almost most of type 2 diabetic patients $(77.8 \%)$. It was mild among $32.1 \%$ of them, moderate among $25.8 \%$ whereas it was moderately severe or severe among $19.9 \%$ of them.

Moderately severe/severe depression was more reported among patients whose monthly income was 5000 SR or less than those whose monthly income exceeded 10000 SR $(22.4 \%$ versus $15 \%)$. The differences were statistically significant, $p=0.014$. Also, depression was reported among majority of patients who reported family history of depression $(91.9 \%$ ) compared to $75 \%$ of those without family history of depression. Moderately sever and severe depression was reported among $29.7 \%$ of patients with family history of depression compared to $17.9 \%$ of those without family history of depression. The difference was statistically significant, $p=0.016$.

Majority of diabetic patients on insulin therapy (84.8\%) compared to $70.6 \%$ of those without insulin therapy were depressed. Moderately severe or severe depression was reported among $21.4 \%$ of patients on insulin therapy compared to $18.3 \%$ of those without insulin therapy. The difference was statistically significant, $p=0.048$. Majority of patients with diabetic complications (94.2\%) compared to $72.8 \%$ of those without complications were depressed. In addition, moderately severe or severe depression was reported among $26.9 \%$ of complicated patients compared to only $17.8 \%$ of not complicated. The difference was statistically significant, $p=0.007$. Depression and/or its severity were not significantly associated with other studied factors as shown in table 4.

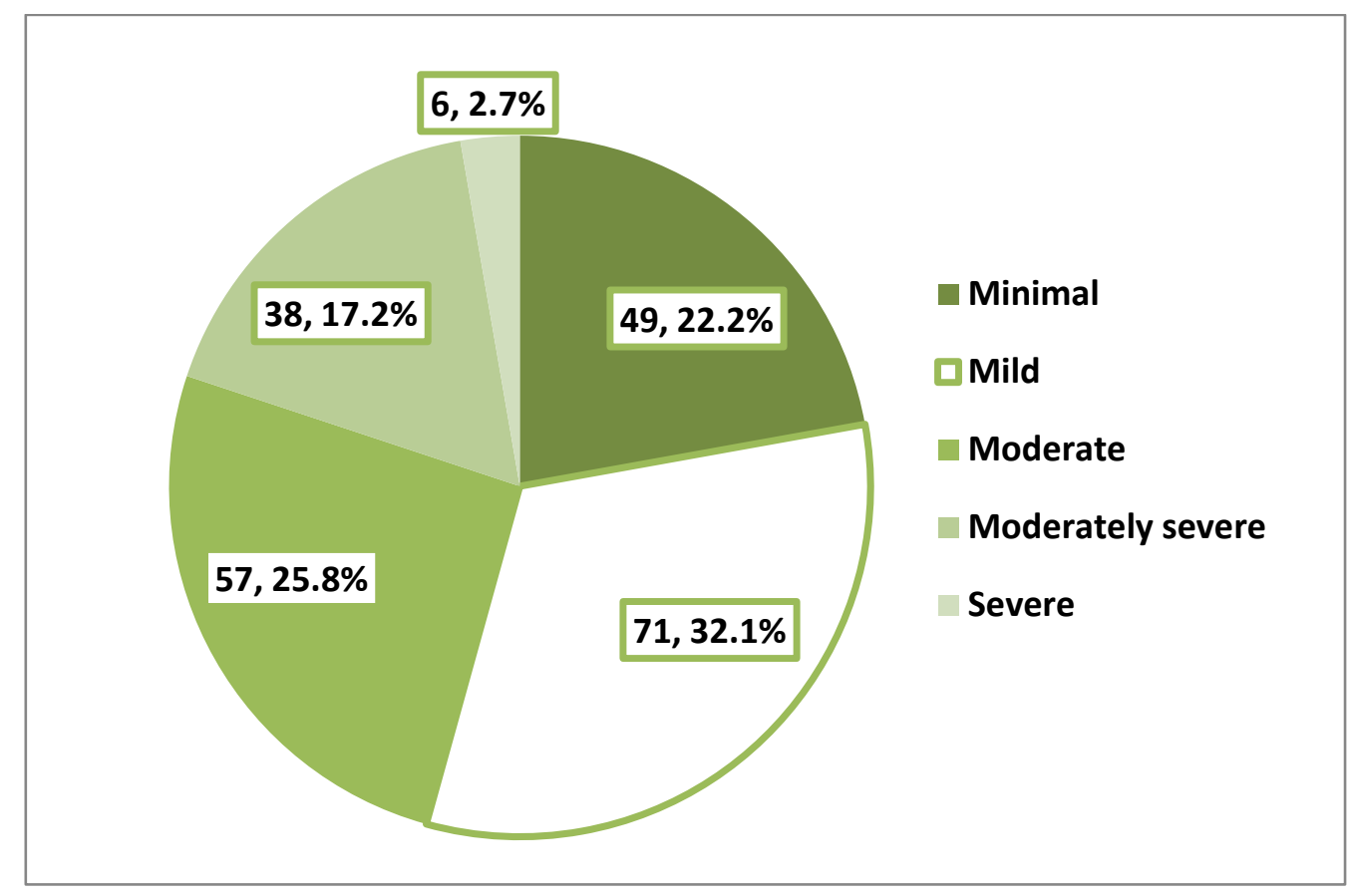

Figure 1: Depression among type 2 diabetic patients, Tabuk city

Table 4: Association between diabetic patient's age and depression severity.

\begin{tabular}{|c|c|c|c|c|c|}
\hline \multirow[t]{4}{*}{ Age (years) } & \multicolumn{4}{|c|}{ Depression } & \multirow{4}{*}{$\begin{array}{c}X^{2} \\
\text { (p-value) }\end{array}$} \\
\hline & No & Mild & Moderate & $\begin{array}{c}\text { Moderately } \\
\text { severe/Severe }\end{array}$ & \\
\hline & $\mathrm{N}=49$ & $\mathrm{~N}=71$ & $\mathrm{~N}=57$ & $\mathrm{~N}=44$ & \\
\hline & $\mathbf{N}(\%)$ & $\mathbf{N}(\%)$ & $\mathbf{N}(\%)$ & $\mathbf{N}(\%)$ & \\
\hline \multicolumn{6}{|l|}{ Age (years) } \\
\hline $30-39(n=45)$ & $12(26.7)$ & $18(40.0)$ & $9(20.0)$ & $6(13.3)$ & \\
\hline $40-49(=56)$ & $11(19.6)$ & $19(33.9)$ & $13(23.2)$ & $13(23.2)$ & 10.23 \\
\hline $50-59(n=77)$ & $18(23.4)$ & $19(24.7)$ & $20(26.0)$ & $20(26.0)$ & $(0.596)$ \\
\hline $60-69(n=34)$ & $7(20.6)$ & $12(35.3)$ & $11(32.4)$ & $4(11.8)$ & \\
\hline$\geq 70(n=9)$ & $1(11.1)$ & $3(33.3)$ & $4(44.4)$ & $1(11.1$ & \\
\hline \multicolumn{6}{|l|}{ Gender } \\
\hline Male $(n=114)$ & $30(26.3)$ & $41(36.0)$ & $26(22.8)$ & $17(14.9)$ & 6.67 \\
\hline Female $(n=107)$ & $19(17.8)$ & $30(28.0)$ & $31(29.0)$ & 27 (25.2) & $(0.083)$ \\
\hline \multicolumn{6}{|l|}{ Marital status } \\
\hline Single $(n=11)$ & $6(54.5)$ & $2(18.2)$ & $2(18.2)$ & $1(9.1)$ & \\
\hline Married $(n=171)$ & 37 (21.6) & $57(33.3)$ & $43(25.1)$ & $34(19.9)$ & 11.04 \\
\hline Divorced $(n=15)$ & $3(20.0)$ & $4(26.7)$ & $3(20.0)$ & $5(33.3)$ & $(0.273)$ \\
\hline Widowed $(n=24)$ & $3(12.5)$ & $8(33.3)$ & $9(37.5)$ & $4(16.7)$ & \\
\hline
\end{tabular}




\begin{tabular}{|c|c|c|c|c|c|}
\hline \multicolumn{6}{|l|}{ Number of children } \\
\hline None $(n=13)$ & $7(53.8)$ & $3(23.1)$ & $2(15.4)$ & $1(7.7)$ & \multirow{5}{*}{$\begin{array}{c}19.06 \\
(0.087)\end{array}$} \\
\hline $1(n=11)$ & $4(36.4)$ & $3(27.3)$ & $1(9.1)$ & $3(27.3)$ & \\
\hline $2(n=15)$ & $3(20.0)$ & $3(13.3)$ & $5(33.3)$ & $5(33.3)$ & \\
\hline $3(n=21)$ & $3(14.3)$ & $8(38.1)$ & $3(14.3)$ & $7(33.3)$ & \\
\hline$\geq 4(n=161)$ & $32(19.9)$ & $55(34.2)$ & $46(28.6)$ & $28(17.4)$ & \\
\hline \multicolumn{6}{|l|}{ Job } \\
\hline Employee $(n=50)$ & $10(20.0)$ & $21(42.0)$ & $11(22.0)$ & $8(16.0)$ & \multirow{4}{*}{$\begin{array}{c}7.83 \\
(0.789)\end{array}$} \\
\hline Private employee $(n=19)$ & $4(21.1)$ & $5(26.3)$ & $6(31.6)$ & $4(21.1)$ & \\
\hline Business ( $n=18)$ & $4(22.2)$ & $6(33.3)$ & $6(33.3)$ & $2(11.1)$ & \\
\hline House wife $(n=100)$ & $21(21.0)$ & $27(27.0)$ & $27(27.0)$ & $25(25.0)$ & \\
\hline Retired $(n=34)$ & $10(29.4)$ & $12(35.3)$ & $7(20.6)$ & $5(14.7)$ & \\
\hline \multicolumn{6}{|l|}{ Income } \\
\hline$\leq 5000(n=134)$ & $35(26.1)$ & $32(23.9)$ & $37(27.6)$ & $30(22.4)$ & \multirow{3}{*}{$\begin{array}{c}16.02 \\
(0.014)\end{array}$} \\
\hline $5001-10000(n=47)$ & $7(14.9)$ & $25(53.2)$ & $7(14.9)$ & $8(17.0)$ & \\
\hline$>10000(n=40)$ & $7(17.5)$ & $14(35.0)$ & $13(32.5)$ & $5(15.0)$ & \\
\hline \multicolumn{6}{|l|}{ Smoking history } \\
\hline Current smoker $(n=54)$ & $12(22.2)$ & $22(40.7)$ & $13(24.1)$ & $7(13.0)$ & \multirow{3}{*}{$\begin{array}{c}4.94 \\
(0.552)\end{array}$} \\
\hline Non-smoker $(n=146)$ & $33(22.6)$ & $41(28.1)$ & $38(26.0)$ & $34(23.3)$ & \\
\hline Ex-smoker $(n=21)$ & $4(19.0)$ & 8 (38.1) & $6(28.6)$ & $3(14.3)$ & \\
\hline \multicolumn{6}{|l|}{ BMI } \\
\hline Underweight ( $n=4)$ & $0(0.0)$ & $3(75.0)$ & $0(0.0)$ & $1(25.0)$ & \multirow{4}{*}{$\begin{array}{c}11.79 \\
(0.463)\end{array}$} \\
\hline Normal $(n=34)$ & $9(25.6)$ & $9(26.5)$ & $10(29.4)$ & $6(17.6)$ & \\
\hline Overweight (n=92) & $24(26.1)$ & $27(29.3)$ & $25(27.2)$ & $16(17.4)$ & \\
\hline Obese $(n=79)$ & $12(15.2)$ & $30(38.0)$ & $18(22.8)$ & $19(24.1)$ & \\
\hline Extremely obese $(n=12)$ & 4 (33.3) & $2(16.7)$ & $4(33.3)$ & $2(16.7)$ & \\
\hline \multicolumn{6}{|l|}{ Family history of depression } \\
\hline Yes $(n=37)$ & $3(8.1)$ & $12(32.4)$ & $11(29.7)$ & $11(29.7)$ & \multirow{2}{*}{$\begin{array}{c}5.77 \\
(0.016)\end{array}$} \\
\hline No $(n=184)$ & $46(25.0)$ & $59(32.1)$ & $46(25.0)$ & $33(17.9)$ & \\
\hline \multicolumn{6}{|c|}{ History of other chronic diseases } \\
\hline Yes $(n=94)$ & $18(19.1)$ & $28(29.8)$ & $28(29.8)$ & $20(21.3)$ & \multirow{2}{*}{$\begin{array}{c}2.12 \\
(0.548)\end{array}$} \\
\hline No $(n=127)$ & $31(24.4)$ & $43(33.9)$ & $29(22.8)$ & $24(18.9)$ & \\
\hline \multicolumn{6}{|l|}{ Number of daily drugs taken } \\
\hline One $(n=23)$ & $7(30.4)$ & $7(30.4)$ & $4(17.4)$ & $5(21.7)$ & \multirow{4}{*}{$\begin{array}{c}7.00 \\
(0.637)\end{array}$} \\
\hline Two $(n=74)$ & $16(21.6)$ & $23(31.1)$ & $18(24.3)$ & $17(23.0)$ & \\
\hline Three $(n=67)$ & $13(19.4)$ & $27(40.3)$ & $15(22.4)$ & $12(17.9)$ & \\
\hline Four and more $(n=57)$ & $13(22.8)$ & $14(24.6)$ & $20(35.1)$ & $10(17.5)$ & \\
\hline \multicolumn{6}{|l|}{ Insulin therapy } \\
\hline Yes $(n=112)$ & $17(15.2)$ & $36(32.1)$ & $35(31.3)$ & $24(21.4)$ & 7.90 \\
\hline No $(n=109)$ & $32(29.4)$ & $35(32.1)$ & $22(20.2)$ & $20(18.3)$ & $(0.048)$ \\
\hline Compliance with diabetic $t$ & & & & & \\
\hline Yes, perfect $(n=105)$ & $31(29.5)$ & $29(27.6)$ & $26(24.8)$ & $19(18.1)$ & 8.67 \\
\hline Yes, to some extent $(n=94)$ & $16(17.0)$ & $34(36.2)$ & $26(27.7)$ & $18(19.1)$ & $(0.193)$ \\
\hline No $(n=22)$ & $2(9.1)$ & $8(36.4)$ & $5(22.7)$ & $7(31.8)$ & \\
\hline Diabetic complications & & & & & \\
\hline Yes $(n=52)$ & $3(5.8)$ & $17(32.7)$ & $18(34.6)$ & $14(26.9)$ & 11.99 \\
\hline No $(n=169)$ & $46(27.2)$ & $54(32.0)$ & $39(23.1)$ & 30 (17.8) & $(0.007)$ \\
\hline Number of follow-up visits & & & & & \\
\hline One $(n=17)$ & $7(41.2)$ & $4(23.5)$ & $3(17.6)$ & $3(17.6)$ & \\
\hline Two $(n=86)$ & $20(23.3)$ & $25(29.1)$ & $24(27.9)$ & $17(19.8)$ & 6.77 \\
\hline Three $(n=85)$ & $15(17.6)$ & $33(38.8)$ & $20(23.5)$ & $17(20.0)$ & $(0.661)$ \\
\hline More than three $(n=33)$ & $7(21.2)$ & $9(27.3)$ & $10(30.3)$ & $7(21.2)$ & \\
\hline Fasting blood glucose (mg & & & & & \\
\hline Good $(n=66)$ & $9(13.6)$ & $23(34.8)$ & $18(27.3)$ & $16(24.2)$ & 5.00 \\
\hline Borderline ( $n=114)$ & $29(25.4)$ & $36(31.6)$ & $30(26.3)$ & $19(16.7)$ & $(0.544)$ \\
\hline Poor $(>180)(n=41)$ & $11(26.8)$ & $12(29.3)$ & $9(22.0)$ & $9(22.0)$ & \\
\hline $\mathrm{HbA1c} \%$ & & & & & \\
\hline$<9 \%(n=162)$ & $37(22.8)$ & $54(33.3)$ & $39(24.1)$ & $32(19.8)$ & 1.10 \\
\hline$>9 \%(n=59)$ & $12(20.3)$ & $17(28.8)$ & $18(30.6)$ & $12(20.3)$ & $(0.777)$ \\
\hline
\end{tabular}




\section{DISCUSSION}

It has been documented that the existence of depressionamong patients with diabetes is associated with adverse diabetic complications. ${ }^{25}$ Therefore, this study was carried out to explore the possible association between diabetes and depression and type 2 diabetes and its determinants in Tabuk, Saudi Arabia.

The prevalence of depression among type 2 diabetic patients in the present study was $77.8 \%$, it was mild among $32.1 \%$ of them and moderately severe or severe among $19.9 \%$. In another study carried out in Jeddah (2005), it was 48\%. ${ }^{26}$ In Riyadh, AL-Baik et al (2013) reported a prevalence of $45.8 \% .{ }^{27}$ In Makkah (2010), the prevalence was $41.9 \% .{ }^{28}$ In the Qatif area, a prevalence of $14.5 \%$ for depression among diabetic has been reported. ${ }^{29}$

Internationally, Raval et al. (2010) in North India reported a prevalence of $41 \%$ of clinically significant depression. ${ }^{30}$ In Iran (2007) Khamseh et al. reported a major depression prevalence of $71.8 \%$ among patients with diabetes (both types; type 1 and type 2). ${ }^{31}$

This difference in prevalence rates of depression among diabetic patients between different studies either local or international could be explained by the fact that some studies included only major depression according to Diagnostic and Statistical Manual of Mental Disorders, IV (DSM VI) criteria while others, like the present study included depression as one category, in addition to different tools used for diagnosis of depression and different patients' background criteria.

In agreement with others, ${ }^{28,32}$ the present study confirmed a significant relationship between family history of depression and developing depression among diabetic patients.

In the current survey, presence of diabetic complications was a significant predictor for depression. Earlier studies confirmed this finding. ${ }^{28,31-34}$ Moreover, it has been reported that having more than two diabetic complications increased odds ratio of having depression by almost three times. ${ }^{34}$ Additionally, Lustman et al ${ }^{35}$ reported that longer depression period increased the risk of developing diabetic retinopathy as a result of long periods of poor glycaemic control. Also, in a meta-analysis published by De Groot et $\mathrm{al}^{10}{ }^{10}$ a significant association between diabetic complications (retinopathy, neuropathy, nephropathy, sexual dysfunction and macrovascular complications) and depression was confirmed.

The present study showed a higher significant rate of depression among those treated with insulin. Al-Mouaalamy in Saudi Arabia has reported a significant increase in depression rate among patients treated with insulin. ${ }^{23,26}$ In addition, Peyrot and Ruben ${ }^{34}$ documented that risk to develop depression increased by forty percent among diabetics type 2 who were using insulin. This finding can be explained by the fact that uncontrolled and/or complicated patients were usually using insulin.

In agreement with others, ${ }^{36}$ we did not find an association between gender and depression among diabetics. However, other studies reported that female patients were more prone to depression than male patients. ${ }^{37-40}$

Uncontrolled diabetes, as indicated by levels of fasting blood sugar and glycosylated haemoglobin percentage, was not significantly associated with depression in the present study. Other studies reported that uncontrolled diabetes would increase the risk of having depression. ${ }^{32-34}$ However other studies ${ }^{10}$ did not observe significant differences in average $\mathrm{HbA} 1 \mathrm{C}$ by depression status.
Limitations to the current study included the cross-sectional nature of the study design which did not prove causality, carrying out the study in one city in the kingdom that makes it difficult to generalize the findings to other areasas well as the use of self-report questionnaires, as literature documented that rate of depression is higher in self-report questionnaires than psychiatric interview. ${ }^{41}$

In conclusion, depression was prevalent among type 2 diabetic patients attended general hospitals in Tabuk city. We recommended implementing screening program for diabetic patients regarding depression through trained family physicians especially for high risk groups as well as referral of those suffering from severe depression to psychiatrists as early as possible.

\section{REFERENCES}

1. Sharp LK, Lipsky MS. Screening for Depression across the lifespan: a review of measures for use in primary care settings. Am Fam Physician. 2002 Sep 15; 66(6): 1001-1009.

2. King H, Auburt RE, Herman WH. Global burden of diabetes 1 . 1995-2025: prevalence, numerical estimates, and projections. Diabetes Care 1998; 21: 1414-31.

3. Al-Nozha MM, Al-Maatouq MA, Al-Mazrou YY, Al-Harthi SS, Arafah MR, Khalil MZ, et al. Diabetes mellitus in Saudi Arabia. Saudi Med J 2004;25:1603-1610.

4. Anderson RJ, Freedland KE, Clous RE, Lustman PJ. Theprevalence of comorbid depression in adults with diabetes: ameta-analysis. Diabetes Care 2001; 24: 1069-1078.

5. Ali S, Stone MA, Peters JL, Davies MJ, Khunti K. The prevalence of co-morbid depression in adults with type 2 diabetes: a systematic review and meta-analysis. Diabet Med 2006; 23: 1165-1173.

6. Dunbar JA, Reddy P, Davies-Lameloise N, Philpot B, Laatikainen T, Kilkkinen $A$, et al. Depression: an important comorbidity with metabolic syndrome in a general population. Diabetes Care 2008; 31: 2368-2373.

7. Reddy $P$, Philpot B, Ford D, Dunbar JA. Identification of depression in diabetes: the efficacy of PHQ-9 and HADS-D. British Journal of General Practice, June 2010 e239-e245.

8. American Diabetes Association. Depression. Available from: URL: http://www.diabetes.org. (Last assessed October 9, 2007)

9. de Groot M, Anderson R, Freedland KE, Clouse RE, Lustman 4. PJ. Association of depression and diabetes complications: a metaanalysis. Psychosomatic Med 2001; 63: 619-30.

10. Egede LE, Zheng D, Simpson K. Comorbid depression is associated with increased health care use and expenditures in individuals with diabetes. Diabetes Care 2002; 25: 464-70.

11. Katon WJ, Simon G, Russo J, Von Korff M, Lin EH, Ludman E, et al. Quality of depression care in a population-based sample of patients with diabetes and major depression. Med Care 2004; 42: 1222-9.

12. Lin EH, Katon W, Von Korff M, Rutter C, Simon GE, Oliver M, et al. Relationship of depression and diabetes self-care, medication adherence, and preventive care. Diabetes Care 2004; 27: 2154-60.

13. Katon WJ, Rutter C, Simon G, Lin EH, Ludman E, Ciechanowski $P$, et al. The association of comorbid depression with mortality in patients with type 2 diabetes. Diabetes Care 2005; 28: 2668-72.

14. Regen F, Merkl A, Heuser I, Dettling M, Anghelescu I. Diabetes and depression. Dtsch Med Wochenschr 2005; 
130 (17):1097-1102.

15. Braunwald E, Fauci AS, Kasper DL, Longo DL, Jameson JL. Harrison's Principles of Medicine. 15thedition, New york: Mc Grow- Hill 2001.

16. Black SA, MarkidesKS, Ray LA. Depression predicts increased incidence of adverse health outcomes in older mexicanamericans with type 2 diabetes. Diabetes Care 2003; 26: 2822-8.

17. Arroll B, Goodyear-Smith F, Crengle S, Gunn J, Kerse N, Fishman T, Falloon K, Hatcher S. Validation of PHQ-2 and PHQ-9 to screen for major depression in the primary care population. Ann Fam Med. 2010;8(4):348-53.

18. Nease DE Jr, Maloin JM. Depression screening: a practical strategy. J FamPract. 2003;52(2):118-124.

19. Joseph N, Unnikrishnan B, Babu YPR, Kotian MS, Nelliyanil $M$. Proportion of depression and its determinants among type 2 diabetes mellitus patients in various tertiary care hospitals in Mangalore city of South India. 2013;17(4):681-688

20. Campbell KB, Braithwaite SS. Hospital Management of Hyperglycemia. Clinical Diabetes 2004; 22 (2): 81-88.

21. Gallagher EJ, Bloomgarden ZT, Le Roith D. Review of hemoglobin A1C in themanagement of diabetes. Journal of Diabetes, 2009, 1:9-17.

22. Bartlett JE, Kotrlik JW, Higgins CC. Organizational Research: Determining Appropriate Sample Size in Survey Research. Information Technology, Learning, and Performance Journal 2001; 19(1):43-50.

23. Liu SI, Yeh ZT, Huang HC, Sun FJ, Tjung JJ, Hwang LC, Shih $\mathrm{YH}$, Yeh AW. Validation of Patient Health Questionnaire for depression screening among primary care patients in Taiwan. Compr Psychiatry. 2011; 52(1):96-101.

24. Arroll B, Goodyear-Smith F, Crengle S, Gunn J, Kerse N, Fishman T, Falloon K, Hatcher S. Validation of PHQ-2 and PHQ-9 to screen for major depression in the primary care population. Ann Fam Med. 2010;8(4):348-53.

25. Lin EHB, Rutter CM, Katon W, Heckbert SR, Ciechanowski P, Oliver MM, Ludman EJ, Young BA, Williams LH, McCulloch DK, Von Korff M. Depression and advanced complications of diabetes. Diabetes Care. 2010; 33(2):264-269.

26. Al Mouaalamy NA. Prevalence of depression among type 2 diabetic patients atteding diabetic clinic at primary health care centers in Jeddah 2004-2005 [dissertation]. Joint Programme of Family and Community Medicine, Jeddah - KSA, 2005.

27. AL-Baik MZ, Moharram MM, Elsaid T, Al-Baik S, AIDahan S, Alkhadhrawi N, et al. Screening for depression in diabetic patients. Int J Med Sci Public Health 2014; 3:156-160.

28. Trabulsi FA, Almasaodi KA. Depression among type 2 diabetic patients in Al-Eskan Avenue in Makkah, 2010. American Journal of Research Communication. 2013; 1(10): 49-68.

29. Al-Muzien NA, Al-Sowielem LS.Prevalence of depression in diabetics attending primary healthcare centers in the Eastern Province of Saudi Arabia. J Bahrain Med Soc 2014; 25(1): 14-18.

30. Raval A, Dhanaraj E, Bhansali A, Grover S, Tiwari P. Prevalence \& determinants of depression in type 2 diabetes patients in a tertiary care centre. Indian J Med Res. 2010 Aug; 132:195-200.

31. Khamseh ME, Baradaran HR, Rajabali H. Depression and diabetes in Iranian patients: a comparative study. Int J Psychiatry Med. 2007; 37(1): 81-86.

32. Tellez-Zenteno JF, Cardiel MH. Risk factors associated with depression in patients with type 2 diabetes mellitus. Arch Med Res 2002; 33(1):53-60.

33. Xu L, Ren J, Cheng M, Tang K. Depressive symptoms and risk factors in Chinese persons with type 2 diabetes. Arch Med Res 2004; 35(4):301-7.

34. Peyrot M, Rubin RR. Persistence of depressive symptoms in adult diabetic patients. 1999; 22(3): 448-452.

35. Lustman P, Anderson R, Freedland K, de Croot M, Carney R, Clouse R. Depression and poor glycemic control. Diabetes Care 2000; 23:934-942.

36. Kovacs M, Obrosky DS, Goldston D, Drash A. Major depressive disorder in youths with IDDM: a controlled prospective study of course and outcome. Diabetes Care 1997; 20:45-51.

37. Joseph N, Unnikrishnan B, Babu YPR, Kotian MS, Nelliyanil M. Proportion of depression and its determinants among type 2 diabetes mellitus patients in various tertiary care hospitals in Mangalore city of South India. 2013;17(4):681-688.

38. Katon W, Von KM, Ciechanowski P, Russo J, Lin E, Simon G, et al. Behavioral and clinical factors associated with depression among individuals withdiabetes. Diabetes Care 2004; 27: 914920.

39. Zahida N, Asghara S, Claussena B, Hussaina A. Depression and diabetesin a rural community in Pakistan. Diabetes Research and Clinical Practice 2008; 79(1):124-127.

40. Al-Amera RM, Sobehb MM, Zayedc AA, Al-domid HA. Depression among adults with diabetes in Jordan: risk factors and relationship to blood sugar control Journal of Diabetes and Its Complications 2011;25:247-252.

41. Anderson RJ, Freedland KE, Clouse RE, Lustman PJ. The prevalence of comorbid depression in adults with diabetes: a meta-analysis. Diabetes Care 2001; 24(6): 1069-1078.

\section{Source of Support: Nil. Conflict of Interest: None Declared.}

Copyright: (c) the author(s) and publisher. IJMRP is an official publication of Ibn Sina Academy of Medieval Medicine \& Sciences, registered in 2001 under Indian Trusts Act, 1882.

This is an open access article distributed under the terms of the Creative Commons Attribution Non-commercial License, which permits unrestricted non-commercial use, distribution, and reproduction in any medium, provided the original work is properly cited.

Cite this article as: Faisal Najem Al-Atawi, Mashael Abdullah AlAtawi, Ashwag Ahmed Al-Shehri, Saif Mohammed Al-amri, Nawal Khalaf Al-anazi, Majed S. Al-Qahtani. Prevalence and Determinants of Depression among Type 2 Diabetic Patients in Tabuk City, Saudi Arabia. Int J Med Res Prof. 2016; 2(6):46-53. DOI:10.21276/ijmrp.2016.2.6.009 